\title{
PENGARUH CONTEXTUAL TEACHING AND LEARNING TERHADAP AKTIVITAS DAN HASIL BELAJAR SISWA PADA MATA PELAJARAN IPS KELAS IV SEKOLAH DASAR
}

\author{
Siti Faridah ${ }^{1}$, Mustaji $^{2}$, Waspodo Tjipto Subroto ${ }^{3}$ \\ ${ }^{1}$ Mahasiswa Program Pascasarjana, Prodi Pendidikan Dasar, Universitas Negeri Surabaya, \\ ${ }^{2 \& 3}$ Dosen Pascasarjana, Prodi Pendidikan Dasar, Universitas Negeri Surabaya \\ e-mail: siti7726@gmail.com ${ }^{1}$, mustaji@unesa.ac.id ${ }^{2}$, waspodosubroto@unesa.ac.id ${ }^{3}$
}

\section{Received : Juli 2019}

Reviewed: Agustus 2019

Accepted : September 2019

Published : September 2019
ABSTRACT

This study is purposed to gain information of the effect of contextual teaching and learning to the activities and the result of social study subject of the fourth grader students. This research was conducted at SDN Kesek 2 Labang elementary school of Bangkalan with the students of IV-A and IV-B 2015/2016 as the subject. The type of the research was experimental research by using pre-post test control group design. The instruments used are the items of the learning result. Each of the variable items was tested by validity checker using the corektion between product moment and reliability test using Alpha cronbach's in valid and reliable result, kolmogorov smirnov was used to the normality test, while independent sample " $t$ " test was used for the homogenity test. The result was normal and homogen. The data which had been collected was analyzed with T test using SPSS Version 21.The hypotetical test result explains that $f$ value obtained is 1,689 and significance valve is 0,05. Based on these results the hyipothesis is accepted it can be concluded that contextual teaching and learning can significantly improve the learning output ot the fourth grader students of SDN Kesek 2 Bangkalan.

Keywords: Contextual teaching and learning, Activities, Students learning results, Social studies.

\section{ABSTRAK}

Penelitian ini bertujuan untuk mengetahui pengaruh pembelajaran contextual teaching and learning terhadap aktivitas dan hasil belajar siswa kelas IV Sekolah Dasar. Penelitian ini dilakukan di SDN Kesek 2 Labang Bangkalan dengan subjek penelitian adalah siswa kelas IV-A dan IV-B tahun pelajaran 2015/2016. Jenis penelitian yang dilakukan adalah penelitian eksperimen dengan bentuk desain penelitian pretest-posttest control group design. Instrumen yang digunakan untuk mengumpulkan data adalah soal-soal hasil belajar. Butir soal variabel hasil belajar telah diujicobakan melalui uji validitas menggunakan korelasi Product Moment dan uji reliabilitas menggunakan Alpha Cronbach's dengan hasil yang valid dan reliabel. Uji normalitas data menggunakan Kolmogorov Smirnov, sedangkan uji homogenitas menggunakan rumus Independent Sample t test dengan hasil kedua kelas berdistribusi normal dan homogen. Data-data yang telah berhasil dikumpulkan kemudian dianalisa dengan Uji $t$ dengan memanfaatkan komputer dengan sistem seri program statistic (SPSS version 21). Hasil pengujian hipotesis menjelaskan nilai f hitung yang didapat yaitu sebesar 1,689 dan nilai signifikansi sebesar 0,05, hasil pengujian hipotesis tersebut menunjukkan bahwa nilai f hitung yang didapat lebih besar dari nilai $t$ dalam tabel $(0,879>5,61111)$ sedangkan nilai signifikansi tersebut lebih kecil dari nilai $\alpha(0,000<0,05)$. Berdasar hasil tersebut, maka hipotesis diterima, artinya terdapat pengaruh yang signifikan antara pembelajaran contextual teaching and learning terhadap aktivitas dan hasil belajar siswa kelas IV SDN Kesek 2 Labang Bangkalan.

Kata Kunci: Contextual Teaching and Learning, Aktivitas, Hasil Belajar Siswa, IPS. 


\section{PENDAHULUAN}

Pelaksanaan proses pembelajaran di sekolah dasar berkaitan dengan berbagai kebijakan atau peraturan yang mendukung pembelajaran di SD diantaranya terdapat dalam Peraturan Pemerintah No. 19 Tahun 2005 tentang Standar Nasional Pendidikan pasal 19 ayat 1 bahwa "Proses pembelajaran pada setiap satuan pendidikan dasar dan menengah harus interaktif, inspiratif, menyenangkan, menantang, dan memotivasi peserta didik untuk berpartisipasi aktif, serta memberikan ruang yang cukup bagi prakarsa, kreativitas, dan kemandirian sesuai dengan bakat, minat, dan perkembangan fisik serta psikologis peserta didik".

Dalam standar kompetensi dan kompetensi dasar tingkat SD/MI dalam peraturan Menteri Pendidikan Nasional Nomor 22 Tahun 2006 tentang standar isi untuk satuan pendidikan dasar dan menengah bahwa IPS merupakan mata pelajaran yang mengkaji seperangkat peristiwa, fakta, konsep, dan generalisasi yang berkaitan dengan isu sosial. Pada masa yang akan datang peserta didik akan menghadapi tantangan berat karena kehidupan masyarakat global selalu mengalami perubahaan setiap saat. Oleh karena itu mata pelajaran IPS dirancang untuk mengembangkan pengetahuan, pemahaman, dan kemampuan analisis terhadap kondisi sosial masyarakat dalam memasuki kehidupan masyarakat yang dinamis.

Tjokrodikaryo (dalam Hidayati, 2008:1.7) memberi batasan IPS meru-pakan suatu pendekatan interdisipliner dari suatu pelajaran ilmu-ilmu sosial.IPS merupakan integrasi dari berbagai cabang ilmu-ilmu sosial, seperti sosiologi, antropologi budaya, psikologi sosial sejarah, geografi, ekonomi, ilmu politik, dan sebagainya. Mata pelajaran tersebut mempunyai ciri-ciri yang sama, sehingga dipadukan menjadi satu bidang studi yaitu Ilmu Pengetahuan Sosial. Menurut Somantri (dalam Wahab, 2009:2.23) pendidikan IPS adalah penyederhanaan, adaptasi dari disiplin ilmu-ilmu sosial dan humaniora, serta kegiatan dasar manusia, yang diorganisir dan disajikan secara ilmiah dan pedagogis/psikologis untuk tujuan pendidikan.

Mata pelajaran IPS SD/MI menurut standar isi KTSP 2006 bertujuan agar peserta didik memiliki kemampuan yaitu: (1) mengenal konsep-konsep yang berkaitan dengan kehidupan masyarakat dan lingkungannya; (2) memiliki kemampuan dasar untuk berfikir logis dan kritis, rasa ingin tahu, inkuiri, memecahkan masalah, dan keterampilan terhadap nilainilai sosial; (3) memiliki komitmen kesadaran terhadap nilai-nilai sosial dan kemanusiaan; dan (4) memiliki kemampuan berkomunikasi, bekerja sama, dan berkompetisi dalam masyarakat yang majemuk di tingkat lokal, nasional, dan global.

Berdasarkan Depdiknas (2007) masih banyak permasalahan- permasalahan pelaksanaan standar isi pada mata pelajaran IPS. Guru dalam menerapkan metode pembelajaran lebih menekankan pada aktivitas guru, bukan aktivitas siswa. Pembelajaran yang dilakukan guru kurang variatif, guru lebih banyak menggunakan metode ceramah, serta saran untuk mendukung pembelajaran IPS masih sangat minim.

Berdasarkan refleksi bersama tim kolaborasi bahwa pembelajaran IPS mengalami beberapa permasalahan dalam pelaksanaan pembelajaran IPS di kelas IV SD, kualitas pembelajaran IPS rendah, Dalam menyampaikan materi guru kurang menarik respon siswa dengan memberikan umpan balik berupa pertanyaan kepada siswa tentang materi yang diajarkan. Hal tersebut menyebabkan peran guru lebih dominan dalam menjelaskan materi. Diskusi kelompok tidak pernah dilakukan dalam pembelajaran. Siswa kurang diberikan kesempatan untuk mengungkapkan materi yang sedang di pelajari. Guru kurang dapat menciptakan suasana pembelajaran yang menarik dan menyenangkan.

Aktivitas siswa dalam pembelajaran masih rendah. Hal ini ditunjukan dari keterlibatan siswa yang kurang dalam pembelajaran. Siswa kurang memberikan respon terhadap pertanyaan yang diberikan guru dan masih takut mengemukakan pendapatnya sehingga terlihat pasif. Pembelajaran kurang dikaitkan dengan materi yang sedang dipelajari. Diskusi kelompok tidak pernah dilaksanakan sehingga rasa kompetisi dan kerja sama siswa dalam pembelajaran masih kurang.

Permasalahan tersebut didukung oleh data dokumen hasil belajar siswa kelas IV semester I tahun pelajaran 2014/2015 pada mata pelajaran IPS menujukan rata-rata 55,5 dan ketuntasan klasikal hanya 41,3\% dari 29 siswa, atau hanya 112 siswa yang berhasil mencapai kriteria ketuntasan minimal yang ditetapkan sekolah yaitu 65. Data hasil belajar ditunjukan dengan nilai terendah 45 dan nilai tertinggi 85. Dengan melihat data hasil belajar dan pelaksanaan pembelajaran pada mata pelajaran IPS tersebut maka proses pembelajaran harus ditingkatkan kualitasnya.

Untuk mengatasi permasalahan tersebut, maka sebagai upaya untuk meningkatkan kualitas pembelajaran IPS adalah dengan menggunakan model pembelajaran yang sesuai dengan karakteristik anak kelas IV dengan tahap berfikir konkrit. Cobern (dalam Suprijono, 2011:79). Berdasarkan pemikiran tersebut, maka pembelajaran harus diciptakan semirip mungkin dengan situasi dunia nyata.Pembelajaran yang dimaksud adalah pembelajaran 
kontekstual. Oleh karena itu peneliti merencakan melakukan penelitian dengan menerapkan contextual teaching and learning (CTL). Rencana ini berdasarkan pertimbangan pada beberapa kelebihan CTL.

Pembelajaran CTL merupakan konsep belajar mengajar yang membantu pendidik menghubungkan isi materi pembelajaran dengan situasi dunia nyata, memotivasi peserta didik membuat hubungan antara pengetahuan dan penerapannya dengan kehidupan nyata seperti anggota keluarga, warga negara, dan pekerja, serta mempersyaratkan belajar dan bekerja keras (Rifa'i dan Anni, 2009:236) guru dikatakan telah menerapkan pedekatan CTL apabila menempuh tujuh komponen yaitu konstruktivisme, inkuiri, bertanya, masyarakat belajar, pemodelan, refleksi, penilaian sebenarnya. Menurut Anisa (2009) ada beberapa kelebihan dalam pembelajaran CTL, yaitu: (a) pembelajaran lebih bermakna; (b) pembelajaran lebih produktif dan mampu menumbuhkan penguatan konsep kepada siswa karena pembelajaran CTL, menuntut siswa menemukan sendiri bukan menghafal; (c) menumbuhkan keberanian siswa untuk mengemukakan pendapat tentang materi yang dipelajari; (d) menumbuhkan rasa ingin tahu tentang materi yang dipelajari dengan bertanya kepada guru; (e) menumbuhkan kemampuan dalam bekerja sama dengan teman yang lain untuk memecahkan masalah yang ada; (f) siswa dapat membuat kesimpulan sendiri dari kegiatan pembelajaran.

Pembelajaran CTL adalah membantu siswa memahami makna materi pelajaran yang mereka pelajari, kemudian menghubungkan dengan kontek kehidupan mereka sehari-hari. Media dalam pembelajaran CTL dapat berupa situasi alamiah, benda nyata, alat peraga, perlu dirancang agar dapat belajar lebih bermakna. Agar pelaksanaan pembelajaran dengan pendekatan CTL dapat dilakukan secara efektif (dalam Daryanto, 2010:40).

Dengan melakukan pedekatan CTL akan membuat belajar menjadi lebih bermakna dengan kerjasama dalam kelompok dan mengkontruk sendiri pengetahuannya sehingga menciptakan suasana pembelajaran yang menyenangkan. Pembelajaran yang semula pasif menjadi aktif, dan siswa menjadi aktif, kreatif dan krtis. Dengan melakukan strategi pembelajaran tersebut diarahkan agar pembelajaran lebih efektif dan tujuan pembelajaran dapat tercapai.

Aktivitas adalah merupakan prinsip atau asas yang sangat penting di dalam interaksi belajar mengajar. Sebagai rasionalitasnya hal ini juga mendapatkan pengakuan dari berbagai ahli pendidikan. Frobel mengatakan bahwa "manusia sebagai pencipta". Dalam ajaran agama pun diakui bahwa manusia adalah sebagai pencipta yang kedua (setelah Tuhan). Secara alami anak didik memang ada dorongan untuk mencipta. Anak adalah suatu organisme yang berkembang dari dalam. Prinsip utama yang dikemukakan Frobel bahwa anak itu harus bekerja sendiri. Untuk memberikan motivasi, maka dipopulerkan suatu semboyan "berpikir dan berbuat".

Dalam dinamika kehidupan manusia, berpikir dan berbuat sebagai suatu rangkaian yang tidak dapat dipisahkan. Begitu juga dalam belajar sudah barang tentu tidak mungkin meninggalkan dua kegiatan itu, berpikir dan berbuat. Seseorang yang telah berhenti dan berbuat perlu diragukan eksistensi kemanusiaannya.

Montessori juga menegaskan bahwa anak-anak memiliki tenaga-tenaga untuk berkembang sendiri, membentuk sendiri. Pendidik akan berperan sebagai pembimbing dan mengamati bagaimana perkembangan anak didiknya. Pernyataan Montessori ini memberikan petunjuk bahwa yang lebih banyak melakukan aktivitas di dalam pembentukan diri adalah anak itu sendiri, sedangkan pendidik memberikan bimbingan dan merencanakan segala kegiatan yang akan diperbuat oleh anak didik.

Dalam hal kegiatan belajar ini, Rousseau memberikan penjelasan bahwa segala pengetahuan itu harus diperoleh dengan pengamatan sendiri, pengalaman sendiri, penyelidikan sendiri, dengan bekerja sendiri, dengan fasilitas yang diciptakan sendiri, baik secara rohani maupun teknis.

Dengan mengemukakan beberapa pandangan dari berbagai ahli tersebut di atas, jelas bahwa dalam kegiatan belajar, subyek didik/siswa harus aktif berbuat. Dengan kata lain, bahwa dalam belajar sangat diperlukan adanya aktivitas. Tanpa aktivitas, proses belajar tidak mungkin berlangsung dengan baik. (Sardiman, 2012:96).

Hasil penelitian yang mendukung dalam pemecahan masalah ini adalah penelitian yang dilakukan oleh Khoiriyah (2010) dengan judul "Pemanfaatan Lingkungan Sekitar dengan Pendekatan CTL untuk Meningkatkan Hasil Belajar Mata Pelajaran IPS kelas IV SD". Temuan penelitian adalah siswa mejadi antusias, lebih berani bertanya atau menanggapi pertanyaan dari teman dan guru serta lebih kreatif dalam pembelajaran. Berdasarkan uraian tersebut maka peneliti mengkaji melalui penelitian eksperimen ini dengan Penerapan contextual teaching and learning. Untuk Meningkatkan Kualitas Pembelajaran IPS Pada Siswa Kelas IV SD.

\section{METODE}

Jenis penelitian yang digunakan dalam penelitian dengan judul "Pengaruh Contextual Teaching and Learning Terhadap Aktivitas dan Hasil Belajar Siswa pada Mata 
Pelajaran IPS Kelas IV SD" adalah jenis penelitian eksperimen. Dimana dalam penelitian ini terdapat dua variabel, yaitu variabel terikat dan variabel bebas.

Jenis penelitian kuantitatif yang akan dilaksanakan adalah jenis penelitian eksperimen karena bertujuan untuk mengukur pengaruh variabel bebas yaitu penggunaan CTL ( $\mathrm{X}$ ) terhadap variabel terikat yaitu aktivitas siswa $\left(\mathrm{Y}_{1}\right)$ dan hasil belajar $\left(\mathrm{Y}_{2}\right)$.

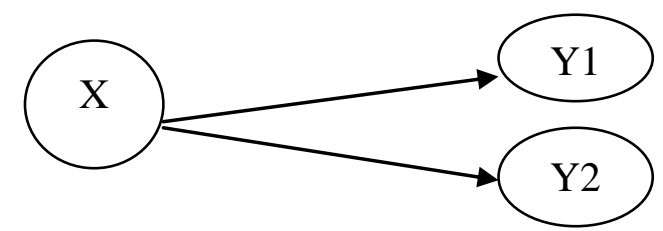

Bagan 1. Hubungan antara variabel bebas dan variabel terikat

Rancangan penelitian yang digunakan adalah Eksperimen. Penentuan populasi tidak dilakukan secara acak didasarkan pada tingkat kemampuan anak. Rancangan penelitian true experimental (eksperimen yang betul-betul) mempunyai dua kelompok yaitu kelompok kontrol dan kelompok eksperimen. Kelompok kontrol ini yang akan menjadi pembanding bagi kelompok eksperimen, dan kelompok eksperimen ini yang akan diberikan perlakuan sehingga akan didapat hasil yang akan dibandingkan dengan kelompok kontrol.

Desain penelitian yang digunakan adalah Nonequivalent Control Group Design. Sugiyono (2011:79), desain ini hampir sama dengan pretest Menurut -posttest control group design, hanya pada penelitian ini kelompok eksperimen maupun kelompok kontrol tidak dipilih secara random. Pada desain ini, setelah ditentukannya kelompok kontrol dan kelompok eksperimen maka pengambilan data dilakukan dengan memberikan pretest pada kedua kelompok yang dilakukan pada awal sebelum diberikannya perlakuan pada kelompok eksperimen untuk mengetahui kemampuan awal dari kedua kelompok dan memberikan posttest pada kedua kelompok setelah kelompok eksperimen diberikan perlakuan untuk mengetahui pengaruh pemberian perlakuan tersebut terhadap hasil belajar siswa. Rumus dari desain Nonequivalent Control Group Design dapat digambarkan seperti berikut:

\begin{tabular}{|lll|}
\hline $\mathrm{O}_{1}$ & $\mathrm{X}$ & $\mathrm{O}_{2}$ \\
\hline $\mathrm{O}_{3}$ & $\mathrm{C}$ & $\mathrm{O}_{4}$ \\
\hline
\end{tabular}

(Sugiyono, 2011:76)

Keterangan:
$\mathrm{O}_{1} \quad$ : Hasil pretest kelompok eksperimen
$\mathrm{O}_{2} \quad$ : Hasil posttest kelompok eksperimen
$\mathrm{O}_{3} \quad$ : Hasil pretest kelompok control

$\mathrm{O}_{4} \quad$ : Hasil posttest kelompok control

$\mathrm{X}$ : Perlakuan

Pada kelompok eksperimen pembelajaran dilakukan dengan menggunakan pembelajaran contextual teaching and learning (CTL), sedangkan pada kelompok kontrol pembelajaran dilakukan dengan model pembelajaran konseptual.

Subjek penelitian ini adalah siswa kelas IV-A dan IV-B SDN Kesek 2 Kecamatan Labang Kabupaten Bangkalan. Pemilihan lokasi ini didasarkan pada adanya kelemahan pada hasil belajar siswa di kelas IV. Kemudian sekolah terbuka menerima masukan dari pihak lain untuk menerapkan pembelajaran contextual teaching and learning (CTL) untuk meningkatkan hasil belajar siswa kelas IV. Sampel penelitian adalah 20 untuk masuk kelas kontrol dan 20 siswa untuk masuk kelas eksperimen.

\section{HASIL DAN PEMBAHASAN}

Perangkat pembelajaran yang dibuat terdiri dari lembar pengamatan aktivitas siswa, Rencana Pelaksanaan Pembelajaran (RPP), Lembar Kegiatan Siswa (LKS), dan soal Tes Hasil Belajar (THB). Perangkat pembelajaran sebelum digunakan untuk penelitian terlebih dahulu harus divalidasi oleh ahli/validator. Validator memberikan validasi terhadap perangkat pembelajaran meliputi validasi kelayakan isi, penyajian, bahasa dan keterbacaan. Hasil validasi berupa koreksi, kritik dan saran sebagai dasar untuk merevisi dan melakukan penyempurnaan terhadap perangkat pembelajaran yang dibuat.

Rencana Pelaksanaan Pembelajaran (RPP) merupakan salah satu perangkat pembelajaran yang digunakan sebagai acuan untuk menggambarkan skenario penyajian materi pelajaran yang akan dilakukan oleh guru dalam kegiatan pembelajaran setiap kali pertemuan yang berisikan standar kompetensi, kompetensi dasar, indikator, kegiatan belajar mengajar, sumber belajaran, serta penilaian yang mengacu pada Kurikulum 2013. Validasi terhadap RPP meliputi perumusan indikator keberhasilan belajar. Hasil validasi RPP dari validator dapat dilihat pada tabel 4.1

Hasil validasi RPP tabel 4.1 menunjukkan bahwa rata-rata validasi kelayakan RPP dari validator adalah dengan kategori baik, maka dapat disimpulkan bahwa kategori RPP baik dan layak digunakan dengan sedikit revisi.

Penyusunan instrumen aktivitas siswa didasarkan pada kategori kegiatan siswa selama pembelajaran berlangsung dan sesuai dengan materi pembelajaran yaitu perkembangan produksi, komunikasi dan transportasi. 
Instrumen aktivitas siswa berupa lembar observasi diberikan kepada pengamat (observer) saat pembelajaran berlangsung untuk mengetahui keaktifan siswa dalam pembelajaran yang dilaksanakan. Adapun hasil validasi instrumen aktivitas siswa disajikan dalam tabel 4.2 sebagai berikut.

Berdasarkan tabel di atas, menunjukkan bahwa secara umum hasil validasi instrumen aktivitas siswa yang disusun memiliki kategori sangat baik, maka dapat disimpulkan bahwa kategori instrumen aktivitas siswa sangat baik dan layak digunakan tanpa revisi.

Perangkat pembelajaran yang berupa tes hasil belajar digunakan untuk mendapatkan informasi mengenai ketuntasan belajar siswa pada materi perkembangan produksi, komunikasi dan transportasi. Tes hasil belajar dikembangkan berdasarkan indikator pembelajaran yang telah disusun dalam RPP. Soal-soal dalam tes hasil belajar sebanyak 10 soal obyektif.

Tes hasil belajar yang dibuat peneliti divalidasi oleh validator. Pakar atau validator memberikan validasi terhadap tes hasil belajar meliputi validasi isi, bahasa, dan penulisan butir soal. Hasil validasi kelayakan tes hasil belajar disajikan dalam tabel 4.3

Penilaian aktivitas siswa dilakukan dengan cara observasi. Observasi pada kegiatan siswa berkaitan dengan prinsip penilaian terpadu permendikbud No. 66 tahun 2013 yang berarti penilaian oleh pendidik dilakukan secara terencana, menyatu dengan kegiatan pembelajaran, dan berkesinambungan. Kegiatan dalam pembelajaran CTL hanya bisa diamati pada saat pembelajaran sehingga penilaian yang dilakukan juga dilaksanakan pada saat berlengsungnya pembelajaran, dengan demikian keaktifan siswa dinilai secara terencana, menyatu dengan kegiatan pembelajaran dan berkesinambungan.

Berdasarkan analisis hasil penelitian yang telah dipaparkan di bab IV, maka bab ini akan mendiskusikan hasil penelitian yang difokuskan pada hasil temuan penelitian agar diperoleh pembenaran antara temuan dengan kajian teoritis. Berdasarkan tabel 4.14 dapat diketahui bahwa kedua kelompok data yang diuji yaitu kelompok siswa yang diajar dengan menggunakan model konvesional dan kelompok siswa yang diajar dengan pembelajaran CTL, dari tabel diperoleh nilai signifikasinya berturut-turut sebesar 0,879 dan 0,916 karena kedua kelompok pengujian tersebut memiliki nilai signifikasi > 0,05 atau > $5 \%$ maka dapat disimpulkan bahwa data keaktifan belajar pada masing-masing kelompok adalah berdistribusi normal.

Berdasarkan dari tabel 4.15 untuk uji homogenitas diperoleh nilai signifikasi sebesar 0,944 karena angka signifikasi > 0,05 maka dapat disimpulkan bahwa varians sampel adalah homogen. Sementara, dari tabel 4.16 terlihat bahwa nilai mean aktivitas siswa adalah 5,61111 kemudian dengan melihat hasil uji Independent Sample T test pada tabel 4.16, diperoleh $t_{\text {hitung }}=1,689$ dengan signifikasi 0,05 . Karena signifikasi $<0,05$ dalam taraf kepercayaan $5 \%$ maka $\mathrm{H}_{\mathrm{o}}$ ditolak dan $\mathrm{H}_{\mathrm{a}}$ diterima.

Jadi dalam penelitian ini dapat disimpulkan keaktifan belajar siswa yang menggunakan pembelajaran CTL lebih tinggi dibandingankan dengan aktivitas siswa dengan menggunakan pembelajaran konvensional. Dalam jurnal Kennedy, (Bonwell \& Eison, 1991) menyampaikan bahwa siswa belajar lebih efektif dengan aktif menganalisis, mendiskusikan, dan menerapkan konsep yang telah diajarkan, bukan siswa pasif ketika menyerap informasi.

Tingginya aktivitas siswa tidak terlepas dari peranan guru yang memberikan kesempatan bagi siswa untuk ikut aktif dalam pembelajaran. Siswa diberikan kesempatan untuk lebih bebas, terbuka, dan tertantang untuk ikut berperan serta secara aktif dengan memberanikan diri dan senang memberikan gagasan sebanyak mungkin untuk meningkatkan pemikiran dan sikap kreatif (Munandar, 2012:195).

Dengan demikian dapat disimpulkan bahwa penggunaan pembelajaran CTL berpengaruh terhadap aktivitas siswa. Sesuai dengan penelitian yang dilakukan oleh Sudarmi (2013) menunjukkan pembelajaran CTL lebih miningkatkan aktivitas belajar siswa jika dibandingkan dengan menggunakan metode konvensional.

\section{PENUTUP}

\section{Simpulan}

Berdasarkan pembahasan hasil penelitian pada bab IV dapat disimpulkan bahwa pembelajaran contextual teaching and learning mempunyai pengaruh terhadap keaktifan siswa. Hal ini dapat dilihat dari hasil analisis diperoleh $t_{\text {hitung }}=$ dengan signifikasi 0,05 dan df.38. Oleh karena itu, disimpulkan bahwa siswa mempunyai keaktifan sangat tinggi dalam belajar dengan menggunakan pembelajaran contextual teaching and learning dibandingkan dengan pembelajaran dengan model pembelajaran konvensional

Hal ini terlihat bahwa siswa aktif untuk bekerja sama dengan temannya, bertanggung jawab terhadap tugas yang diberikan oleh guru, bertanggung jawab terhadap segala sesuatu yang berhubungan dengan dirinya sendiri, dan perilaku terhadap lingkungan di sekitarnya. Sedangkan pembelajaran dengan menggunakan model pembelajaran konvensional (ceramah), siswa hanya mendengarkan 
penjelasan dari guru dan masih banyak siswa yang menggantungkan diri kepada temannya yang dirasa lebih mampu, sehingga tanggung jawab siswa terhadap tugas kurang dan kurang terjalin kerjasama antar siswa serta perilaku terhadap lingkungan di sekitarnya juga rendah.

\section{Saran}

Berdasarkan hasil kesimpulan bahwa aktivitas dan hasil belajar siswa dengan penggunaan pembelajaran contextual teaching and Learning, maka pembelajaran contextual teaching and learning ini dapat dijadikan sebagai salah satu alternatif dalam pembelajaran untuk dapat meningkatkan aktivitas dan hasil belajar siswa sehingga akan terwujud sebuah pembelajaran yang aktif, efektif dan menyenangkan.

Pembelajaran contextual teaching and learning juga mempunyai pengaruh terhadap hasil belajar siswa. Terbukti dengan hasil analisis yang menunjukkan bahwa $\mathrm{t}_{\text {hitung }}=$ dengan signifikasi 0,05 dan df. 38. Hal ini karena siswa mempunyai semangat dan antusias yang tinggi untuk belajar sehingga hasil belajar yang diperolehnya pun meningkat. Pembelajaranpun jadi lebih menyenangkan tanpa membuat siswa terbebani akan tugas yang yang diberikan. Berbeda dengan pembelajaran yang menggunakan pembelajaran konvensional sebelum dan sesudah pembelajaran tidak terlihat perbedaan yang signifikan. Jadi, pembelajaran dengan pembelajaran contextual teaching and learning berpengaruh terhadap hasil belajar dibanding pembelajaran dengan menggunakan model pembelajaran konvensional menggunakan materi yang berbeda sehingga peningkatan hasil belajar siswa dapat mencakup subtema lain yang relevan.

\section{DAFTAR PUSTAKA}

Akbar, Sadun. (2011). Pengembangan Kurikulum dan Pengembangan Pembelajaran IPS. Yogyakarta: Cipta Media.

Amelia Pramitasari, Yeniar Indriana \& Jati Ariati. (2011). Hubungan Antara Persepsi Terhadap Matode Pembelajaran Kontekstual dengan motivasi Belajar IPA Siswa Kelas XI, Jurnal Psikologi Undip.

Amri, Sofan. (2013). Pengembangan dan Model Pembelajaran dalam Kurikulum 2013. Jakarta: PT. Prestasi Pustakarya.

Aqib, Zainal. (2013). Model-model Media, dan Strategi Pembelajaran Kontekstual (inovatif). Bandung: Yrama Widya.

Arikunto, Suharsimi. (2010). Prosedur Penelitian: Suatu Pendekatan Praktik (Edisi Revisi). Jakarta: Rineka Cipto.
Bell, Thorsten. (2009). Collaborative Inquiry Learning: Model, Tolls, and Challenges, Internasional Journal of Science Education.

BNSP. (2006). Kurikulum Tingkat Satuan Pendidikan. Jakarta: Depdiknas.

Creswell, J.W. (2009). Research Design: Pendekatan Kuantitatif, dan Mixed, Yogyakarta: Pustaka Pelajar.

Dimyati dan Mudjiono. (2002). Belajar dan Pembelajaran. Jakarta: Rineka Cipta.

Dimyati. (2006). Belajar dan Pembelajaran. Jakarta: Rineka Cipta.

Depdiknas. (2008). Kamus Besar Bahasa Indonesia Edisi 4. Jakarta: PT Gramedia Pustaka Utama.

Gracia Jimenez-Fernandez, Joaquin M.M. Vaquero, Luis Jimenez \& Sylvia Defior. (2011). Dyslexic Children Show Deficits in Implicit Sequence or Contextual Cuening Learning, but not in explicit sequence Learning, Ann. Of Dyslexia (2011) vol. 61 pp. 85-110.

Hasdiana. (2011). Pengaruh Pembelajaran Kontekstual Pada Materi Pelestarian Lingkungan Hidup. Surabaya: Thesis, Unesa.

Hasnawati. (2006). Pendekatan Contextual Teaching Learning Hubungannya dengan Evaluasi Pembelajaran, Jurnal Ekonomi dan Pendidikan, Vol. 3 No.1 April 2006.

Ibnu, Suhadi dkk. (2003). Dasar-dasar Metodologi Penelitian. Malang: Universitas Negeri Malang.

Irnalia. (2011). Penerapan Pembelajaran CTL Menunjukkan Hasil Belajar dan Respon Siswa Lebih Baik dibandingkan dengan Pembelajaran Convensional. Surabaya: Thesis, Unesa.

Istiklah. (2011). Pengembangan Perangkat dengan CTL. Surabaya: Thesis, Unesa.

Johson B, Elaine. (2007). Contextual Teaching and Learning. Bandung: Mizan Learning Center (MLC).

Komalasari, Kokom. (2012). "The Of Contextual Learning In Civic Education On Students Character Development", Asia Pacific Journal of Educators and Education, Vol. 27, pp, 87-103.

Kusmana Suherli. (2010). Model Pembelajaran Siswa Aktif. Jakarta: PT. Multi Kreasi Satudelapan

Nurhadi, Yasin Burhan dkk. (2004). Pembelajaran Kontekstual (CTL) Dan Penerapannya Dalam $K B K$. Malang: Universitas Negeri Malang (UM PRESS). 
Nurhadi. (2012). Menciptakan Pembelajaran IPS Efektif Dan Menyenangkan. Jakarta: Multi Kreasi Satudelapan.

Prasetyo, Bambang \& Jannah, Lina Miftakul. (2011). Metode Penelitian kuantitatis Teori dan Aplikasi. Jakarta : PT. Raja Grafindo Persada

Ranil Coorey and Ann Firth. (2013). "Integred Contectual Learning and Food Science Students".Journal of Food Science Education.Vol.12, 2013.

Rich, W. Clough; Robert P. Lehr. (1996). "Testing Knowledge of Human Gross Anatomy in Medical School; An Applied ContextualLearning Theory Method", Clinical Anatomy, Vol No. 4, pp 263-268.

Riyanto, Yatim. (2010). Paradigma Baru Pembelajaran : sebagai Referensi bagi Guru/Pendidik dalam Implementasi Pembelajaran yang Efektif dan Berkualitas, Ed I. Jakarta: Kencana.

Ruminiati. (2010). Implikasi Teori Sosiologi dan Budaya Patriarkhi dalam Pembelajaran IPS SD Berbasis Gender Pidato Pengukuhan Guru Besar di Universitas Negeri Malang.

Rensus Silalahi, (2011), "Kontribusi Model Pembelajaran Kontekstual Tipe Inkuiri dalam Meningkatkan Motivasi dan Prestasi Belajar Siswa pada Mata Pelajaran Pendidikan Kewarnegaraan". Universitas Pendidikan Indonesia, 2011. Vol. 10. No.: 2 Oktober.

Rusman. (2012). Model-model Pembelajaran Mengembangkan Profesionalisme Guru: Raja Grafindo Prasada. Jakarta.

Rusyana Adun, dkk. (2011). Prinsip-Prinsip Pembelajaran Efektif. Jakarta: Trans Mandiri Abadi.

Sapriya. (2012). Pendidikan IPS. Bandung: Remaja Rosdakarya.

Sardiman. (2012). Interaksi Dan Motivasi Belajar Mengajar. Jakarta: Rajawali Press.

Solihatin, Etin. (2008). Cooperative Learning Model Pembelajaran IPS. Jakarta PT. Bumi Aksara.

Subroto, Waspodo Tjipto. (2009). Bahan Pembelajaran Ilmu Pengetahuan Sosial di Sekolah Dasar. Surabaya: Unesa University Press.

Sudjarweni, V. Wiratna. Statiska Untuk Penelitian. Jogyakarta: Graha Ilmu

Sugiyono. (2012). Metode Penelitian Kuantitatif, Kualitatif, dan R dan D. Bandung: Alfabeta

Sujana, Nana. (2009). Penilaian Hasil Proses Belajar Mengajar. Bandung: PT. Remaja Rosdakarya.

Trianto. (2007). Model-Model Pembelajaran Inovatif Berorientasi Konstruktivistik. Jakarta: Indonesia. 